\title{
Injection-Molded Alumina Prepared with Mg-Containing Binders
}

\author{
K. S. Hwang ${ }^{\dagger}$ and C. C. Hsieh \\ Department of Materials Science and Engineering, National Taiwan University, Taipei 106, Taiwan
}

\begin{abstract}
It is generally accepted that $\mathrm{MgO}$ additions enhance the sintering of alumina. The distribution of the low concentration required is, however, difficult to attain and critical to the final properties and microstructures. To improve the MgO distributions in ceramic injection-molded (CIM) alumina, Mg-containing precursors, Mg-stearate and Mg-acetate, were added during the kneading step of the CIM process, and the results were compared with those from adding $\mathrm{MgO}$ particles. Of the three additives, the Mg-stearate showed the highest sintered density and bending strength. This was attributed to its high molecular weight and it being able to mix with other binder components homogeneously in the liquid state, which leads to a better distribution of the $\mathrm{MgO}$. In contrast, the $\mathrm{MgO}$ powder was kneaded in the solid particle form, and its distribution was not uniform. The Mg-acetate also imparted poorer $\mathrm{MgO}$ distribution because the liquid Mg-acetate dehydrated in the early stage of the kneading and formed solid lumps before it was well mixed into the binder system. The resulting sintered densities and bending strength using these two additives were, therefore, inferior to those for specimens in which Mg-stearate was used.
\end{abstract}

\section{Introduction}

$I^{1}$ is generally accepted that the addition of a small amount of $\mathrm{MgO}$ to alumina promotes densification and facilitates the preparation of alumina with near-theoretical density. ${ }^{1,2}$ Because of the low concentrations needed, proper distribution of the $\mathrm{MgO}$ is difficult to attain and is critical to the properties of the resulting material. A number of methods have been used using Mg-containing chemicals, such as Mg-nitrates, ${ }^{3-6} \mathrm{Mg}$-stearates, ${ }^{6}$ Mg-acetates, ${ }^{6-8}$ and Mg-carbonates. ${ }^{9,10}$ In most studies, these chemicals were dissolved in a solvent or water prior to being mixed with alumina powders. The mixed powder slurries were milled and calcined to form the desired $\mathrm{MgO}$ particles. Most results showed that these $\mathrm{Mg}$-containing chemicals allowed better-sintered properties than the straight $\mathrm{MgO}$ powders.

To make parts with complex shapes, ceramic injection molding (CIM) is frequently chosen as the preferred manufacturing process. ${ }^{11}$ This process starts with the kneading of the ceramic powder and the binder. The kneaded feedstock is then molded, debound, and sintered. To attain high sintered density CIM alumina, $\mathrm{MgO}$-doped alumina powders can be used. It is possible, however, that the $\mathrm{MgO}$ can be provided by adding $\mathrm{Mg}$ containing precursors during kneading and then heating the powder mixture in air to form the needed $\mathrm{MgO}$ particles. In our preliminary study, Mg-containing chemicals, such as Mg-stearate, $\mathrm{Mg}$-acetate, $\mathrm{Mg}$-carbonate, and $\mathrm{Mg}$-nitrate, which have been used for pressed-and-sintered parts in previous studies, were selected as candidates. Because the binder system used in this laboratory consists of polypropylene, paraffin wax, and

M. P. Harmer-contributing editor

Manuscript No. 10064. Received March 18, 2003; approved January 25, 2005. Supported by the National Science Council of the Republic of China under Contract No. NSC84-2216-E-002-033.

Author to whom correspondence should be addressed: e-mail: kshwang@ ccms.ntu.edu.tw stearic acid, the first selection criterion of these Mg-containing precursors was that they have a melting point below $169^{\circ} \mathrm{C}$, which is the melting point of polypropylene. This eliminated $\mathrm{Mg}$-carbonate and Mg-nitrate, the melting points of which were too high. Thus, Mg-acetate and Mg-stearate were selected for further studies. Because very little work has been reported on the effects of $\mathrm{Mg}$-containing chemicals on the properties and processes of CIM alumina, an attempt was thus made in this study to examine whether the $\mathrm{Mg}$-acetate and $\mathrm{Mg}$-stearate are effective $\mathrm{MgO}$ dopants.

\section{Experimental Procedure}

Table I lists the characteristics of the alumina powder used in this study. It had an average particle size of $1.8 \mu \mathrm{m}$. To prepare the CIM specimens, alumina powders at $85 \mathrm{wt} \%$ or $56.8 \mathrm{vol} \%$ were kneaded with a multi-component binder, which consisted of $30 \mathrm{wt} \%$ polypropylene, $65 \mathrm{wt} \%$ paraffin wax, and $5 \mathrm{wt} \%$ stearic acid. To add the $\mathrm{MgO}$, three methods were used. The first method was to add fine $\mathrm{MgO}$ powders that had a BET surface area of $18 \mathrm{~m}^{2} / \mathrm{g}$. The second method was to add $\mathrm{Mg}$-stearate $\left(\mathrm{Mg}\left(\mathrm{C}_{18} \mathrm{H}_{35} \mathrm{O}_{2}\right)_{2}\right)$, and the third, to add $\mathrm{Mg}$-tetrahydrate acetate $\left(\mathrm{Mg}\left(\mathrm{C}_{2} \mathrm{H}_{3} \mathrm{O}_{2}\right)_{2} \cdot 4 \mathrm{H}_{2} \mathrm{O}\right)$. The molecular weights of $\mathrm{MgO}, \mathrm{Mg}$ stearate, and $\mathrm{Mg}$-acetate are 40.3, 590.7, and $214.3 \mathrm{~g} / \mathrm{mol}$, respectively. The amounts of these three additives were calculated so that the final $\mathrm{MgO}$ contents were 580, 1050, 1400, and 1760 ppm. The stearic acid and the polypropylene contents were kept constant in all specimens, while the amount of paraffin wax varied depending on the content of the $\mathrm{MgO}, \mathrm{Mg}$-stearate, and Mg-acetate.

To prepare the feedstock, the alumina powder was heated in a $\Sigma$-blade kneader to $190^{\circ} \mathrm{C}$ and held at that temperature for $1 \mathrm{~h}$ to dry out the absorbed moisture. After drying, polypropylene was mixed into alumina and kneaded for $15 \mathrm{~min}$. The kneader was then cooled to $150^{\circ} \mathrm{C}$ and held there for $20 \mathrm{~min}$ to mix the paraffin wax. Stearic acid and Mg-containing precursors were then added into the mixture and kneaded for another $20 \mathrm{~min}$.

The feedstock was molded into flat specimens, $4 \mathrm{~mm} \times 12$ $\mathrm{mm} \times 100 \mathrm{~mm}$, using the barrel, nozzle, and mold temperatures of $140^{\circ}, 145^{\circ}$, and $40^{\circ} \mathrm{C}$, respectively. To remove the binder in the molded specimen, specimens were immersed in heptane for 3 $\mathrm{h}$ at $60^{\circ} \mathrm{C}$ to remove about $90 \%$ of the soluble binder. The solvent-debound specimens were then heated at $2^{\circ} \mathrm{C} / \mathrm{min}$ to $250^{\circ} \mathrm{C}$, held there for $2 \mathrm{~h}$, and then heated at the same rate to $450^{\circ} \mathrm{C}$. After the removal of the remaining binder components, the specimens were heated again at a rate of $5^{\circ} \mathrm{C} / \mathrm{min}$ to $1000^{\circ} \mathrm{C}$ and held there for $3 \mathrm{~h}$ so that the parts had reasonable strength to sustain the subsequent handling. The cycle time for thermal debinding was about $12 \mathrm{~h}$.

The debound specimens were sintered in air at $1650^{\circ} \mathrm{C}$ for $3 \mathrm{~h}$. After the sintering, the density was measured using the Archimedes method, and the bending strength was tested on surface-ground specimens using a four-point bend tester. To ensure that the binder had been successfully removed, the carbon content in the specimen was measured with a carbon analyzer (LECO CS-244, LECO Co., St. Joseph, MI). For microstructure examinations, specimens were polished and then thermally etched by heating at $5^{\circ} \mathrm{C} / \mathrm{min}$ to $1500^{\circ} \mathrm{C}$ and being held there for $1 \mathrm{~h}$. The microstructures were examined using a scanning elec- 
Table I. Characteristics of the Alumina Powder Used in this Study

\begin{tabular}{lc}
\hline Designation & A-43M \\
Average particle size (laser scattering) & $1.8 \mu \mathrm{m}$ \\
Surface area (BET) $\left(\mathrm{m}^{2} / \mathrm{g}\right)$ & 5.0 \\
Carbon content $(\%)$ & 0.0496 \\
Loss on Ignition & $0.35 \%$ \\
Pycnometer density $\left(\mathrm{g} / \mathrm{cm}^{3}\right)$ & 3.95 \\
Supplier & SDK Co., Tokyo, Japan \\
\hline
\end{tabular}

tron microscope. The mean grain size was calculated using the equation: $D_{\mathrm{m}}=1.5 L_{i}$, where $L_{i}$ is the mean grain intercept of 10 random lines. ${ }^{12}$ The standard deviations were also given to illustrate the uniformity of the grains. These specimens were also examined for the uniformity of $\mathrm{MgO}$ by an electron probe micro-analyzer (EPMA, JXA-8600SX, JEOL Co., Tokyo, Japan). Wavelength dispersive spectra were taken on 50 areas, all with the sizes of $0.25 \mathrm{~mm} \times 0.25 \mathrm{~mm}$. When a magnesium peak was detected, Mg mapping was then performed.

\section{Results}

\section{(1) Thermal Analysis}

Table II shows the melting points of the binder components measured by the differential scanning calorimeter. The melting points of the $\mathrm{Mg}$-stearate and the $\mathrm{Mg}$-acetate were $120^{\circ}$ and $73^{\circ} \mathrm{C}$, respectively. These were lower than the $169^{\circ} \mathrm{C}$ for polypropylene. Thus, both Mg-stearate and $\mathrm{Mg}$-acetate can be kneaded with alumina powders and other binder components without any modification to the existing kneading process, in which the highest kneading temperature used was $190^{\circ} \mathrm{C}$.

Figure 1 shows the TGA curves of the Mg-stearate, Mg-acetate, and $\mathrm{MgO}$. It can be seen that the decomposition of $\mathrm{Mg}$ stearate occurred between $200^{\circ}$ and $480^{\circ} \mathrm{C}$ and about $7 \mathrm{wt} \%$ residue was left after it was heated to $700^{\circ} \mathrm{C}$. This amount was close to the $6.8 \mathrm{wt} \%$ calculated from the chemical formula. The $\mathrm{X}$-ray diffractometer analysis showed that this residue was $\mathrm{MgO}$.

The Mg-tetrahydrate acetate, on the other hand, had two stages of decomposition. The first stage occurred between the melting point of $73^{\circ}$ and $150^{\circ} \mathrm{C}$. After being heated to $150^{\circ} \mathrm{C}$, the weight loss was about $33.0 \%$, which agreed with the water content of $33.6 \%$ calculated from the formula of $\mathrm{Mg}$-tetrahydrate acetate. The second stage of the weight loss began at $340^{\circ} \mathrm{C}$ and ended at about $435^{\circ} \mathrm{C}$. After the specimen was heated to $700^{\circ} \mathrm{C}$, $18.0 \mathrm{wt} \% \mathrm{MgO}$ residue was left, which was close to the calculated $18.7 \%$.

To further understand the thermal behavior of Mg-tetrahydrate acetate, the powder was placed in a beaker and heated in an oven. It was observed that the $\mathrm{Mg}$-acetate melted at $73^{\circ} \mathrm{C}$ and the water contained in the acetate started to evaporate. After being heated to $150^{\circ} \mathrm{C}$, the dehydration was complete and pure $\mathrm{Mg}$-acetate was left in the form of solid lumps. This suggests that the Mg-tetrahydrate acetate, although can be mixed in the liquid form during kneading at $150^{\circ} \mathrm{C}$, it will transform into solid $\mathrm{Mg}$-acetate as kneading proceeds. Therefore, its mixing

Table II. Melting Points of the Binder Components Measured by the Differential Scanning Calorimeter

\begin{tabular}{lc}
\hline Type & Melting point $\left({ }^{\circ} \mathrm{C}\right)$ \\
\hline Mg-stearate & 120 \\
Mg-tetrahydrate acetate & 73 \\
Stearic acid & 72 \\
Paraffin wax & 70 \\
Polypropylene & 169 \\
\hline
\end{tabular}

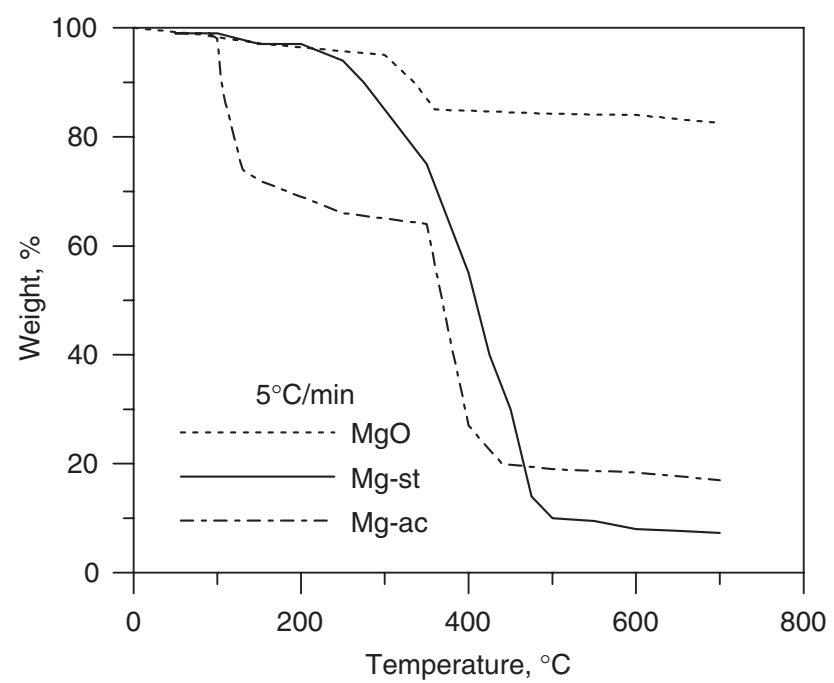

Fig. 1. Thermogravimetric curves of $\mathrm{Mg}$-stearate, Mg-acetate, and $\mathrm{MgO}$.

behavior is in the solid state on a particle scale, similar to that of the $\mathrm{MgO}$ particle.

The $\mathrm{MgO}$ powder also showed weight loss of about $16 \mathrm{wt} \%$ after being heated to $700^{\circ} \mathrm{C}$. An X-ray diffractometer was thus used to examine the compositions in the as-received $\mathrm{MgO}$ powder and the powder that had been heated to $700^{\circ} \mathrm{C}$. The diffraction patterns shown in Fig. 2 confirmed that the $\mathrm{MgO} \cdot x \mathrm{H}_{2} \mathrm{O}$ was present in the as-received powder.

\section{(2) Debinding}

To examine the solvent debinding behavior of each binder component, a solvent dissolution test was performed. The results showed that paraffin wax and stearic acid could be dissolved in heptane, while $\mathrm{Mg}$-stearate and $\mathrm{Mg}$-acetate were insoluble. The weight loss data of the molded specimens suggest that $95 \%$ of the soluble binders, i.e., paraffin wax and stearic acid, were extracted after solvent debinding. The solvent-debound specimens were subsequently thermally debound in air. Previous literature has indicated that the carbon left behind by the binder will impede the sintering of alumina. ${ }^{13,14}$ Thus, the carbon content was monitored to ensure that it did not impair sintering. The results show that the carbon contents in all the specimens were similar

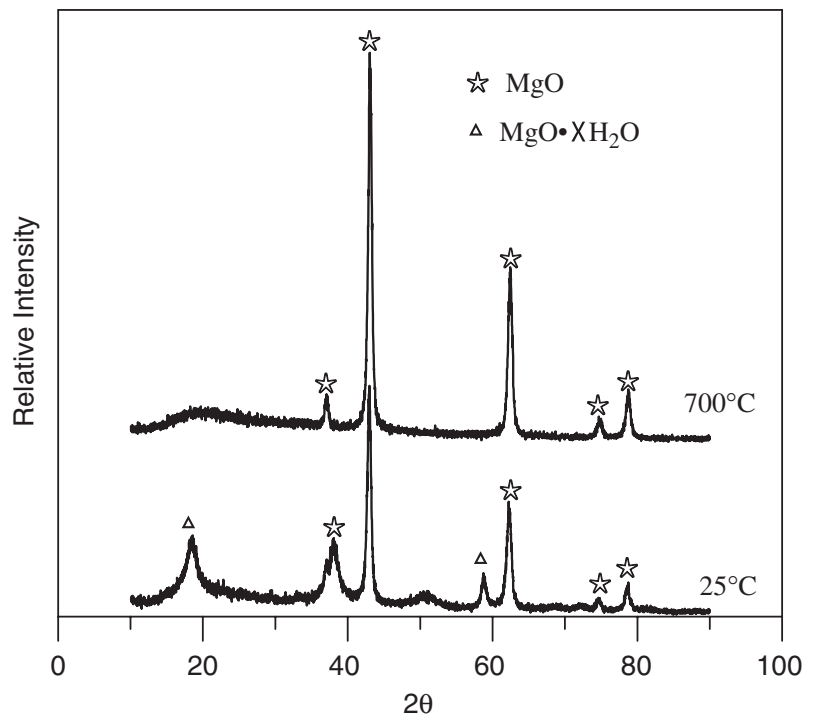

Fig. 2. X-ray diffraction patterns of the $\mathrm{MgO}$ before and after being heated to $700^{\circ} \mathrm{C}$ in air. 
to that of the as-received alumina. This confirmed that the organic materials did not leave residues and thus impede the subsequent sintering.

\section{(3) Sintered Density}

Figure 3 shows the densities of the sintered specimens. When the amount of Mg-stearate increased, the density increased, reaching a maximum of $96.0 \%$, and then decreased slightly. The parts with the addition of $\mathrm{MgO}$ particles exhibited a similar trend. However, the maximum density was only $95.4 \%$, which was obtained with 1400 ppm $\mathrm{MgO}$ additions. When $\mathrm{Mg}$-acetate was used, the densities were slightly lower than those attained using $\mathrm{MgO}$ particles. In all specimens that were prepared with $\mathrm{MgO}$ or Mg-containing precursors, the density passed through a maximum and then decreased slightly as the $\mathrm{MgO}$ content further increased. The same trend was also reported by Peelen ${ }^{15}$ and was believed to be caused by the presence of the second phase.

\section{(4) Microstructure}

The microstructure examination supports the previous density results. Figure 4(a) shows the microstructure of sintered alumina without any $\mathrm{Mg}$-containing additives. The grain sizes were not uniform. Typical large grains with tabular shapes were present, indicating grain boundary energy anisotropy. The pores were quite irregular in shape. The fracture surfaces shown in Fig. 4(b) indicate that most of the fractures are of the transgranular type. Poorly sintered areas are clearly shown and are indicated by the arrows. Figures 5-7 show the microstructures of the specimens that contain $1050 \mathrm{ppm} \mathrm{MgO}$ and were prepared using $\mathrm{MgO}$ particles, $\mathrm{Mg}$-acetate, and $\mathrm{Mg}$-stearate, respectively. With $\mathrm{MgO}$ powders or Mg-acetate, the density was improved, tabular grains disappeared, and the grain size was much more uniform than that of the pure alumina. However, the pore shapes were still quite irregular. The localized low-density areas, as shown in Fig. 5(b) and Fig. 6(b), while less than that in the pure alumina, were still present, indicating a poor $\mathrm{MgO}$ distribution. When the $\mathrm{Mg}$-stearate was used, the uniformity of the grain size and the density were both improved. The pores were also more rounded. These microstructure results are in agreement with those reported for pressed-and-sintered alumina. ${ }^{6}$

Table III shows the average size of the grains shown in Figs. 4-7. The grains in pure alumina are the smallest among the four specimens. However, its standard deviation is the highest, at $3.7 \mu \mathrm{m}$, or $71 \%$ of the mean value, because of the presence of tabular grains. When $\mathrm{MgO}$ was added, the grain size increased slightly, as in previous findings. ${ }^{1,15}$ The grain size uniformity also improved. $\mathrm{Mg}$-acetate and $\mathrm{Mg}$-stearate also show grain sizes similar to those of the $\mathrm{MgO}$-added alumina. It is noted that

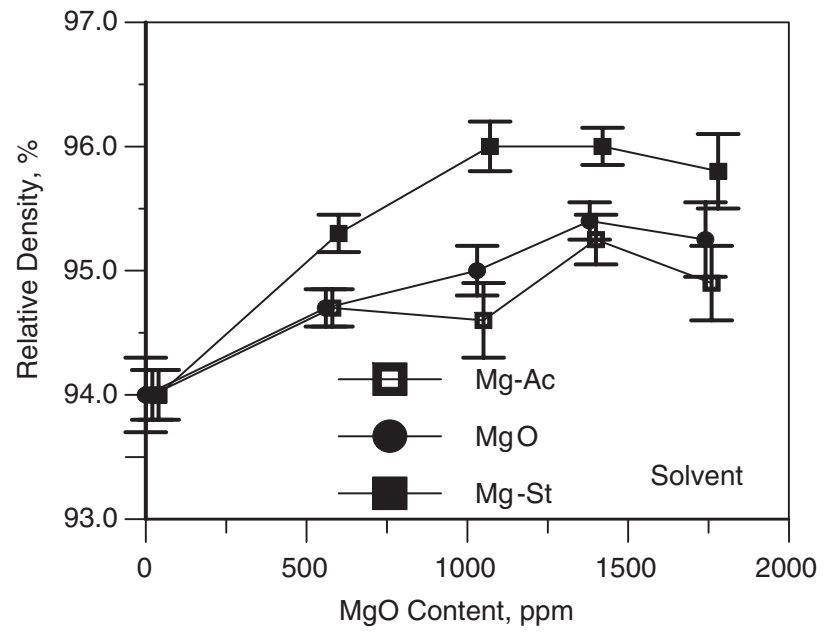

Fig. 3. Sintered densities of the specimens increases as the amount of $\mathrm{MgO}$ increases. (a)

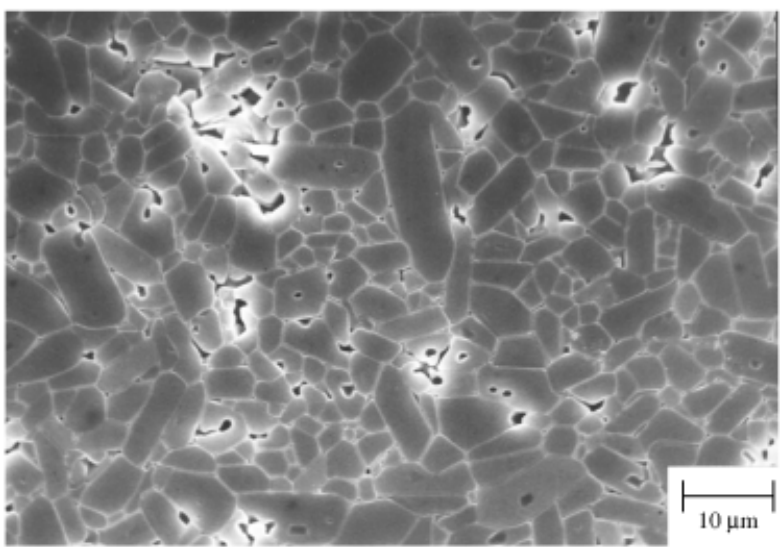

(b)

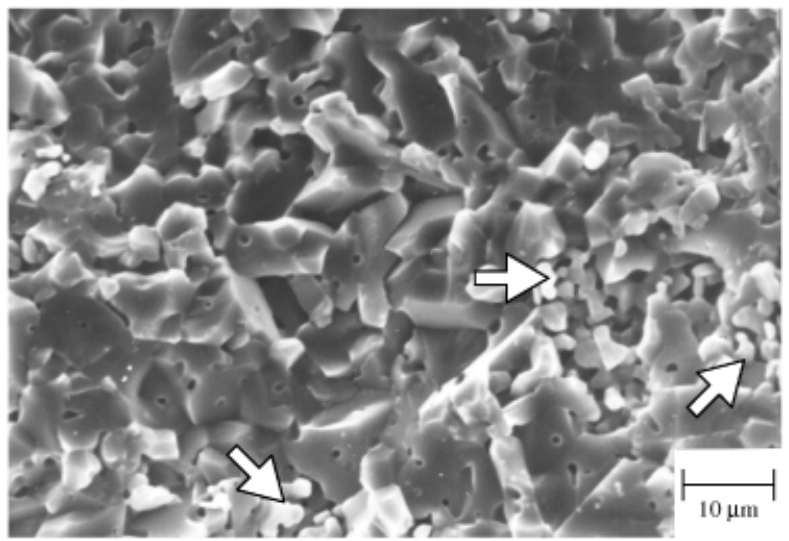

Fig. 4. (a) Microstructure and (b) fracture surface of alumina without $\mathrm{MgO}$ additions showing tabular grains and some poorly sintered areas, as indicated by the arrows.

(a)

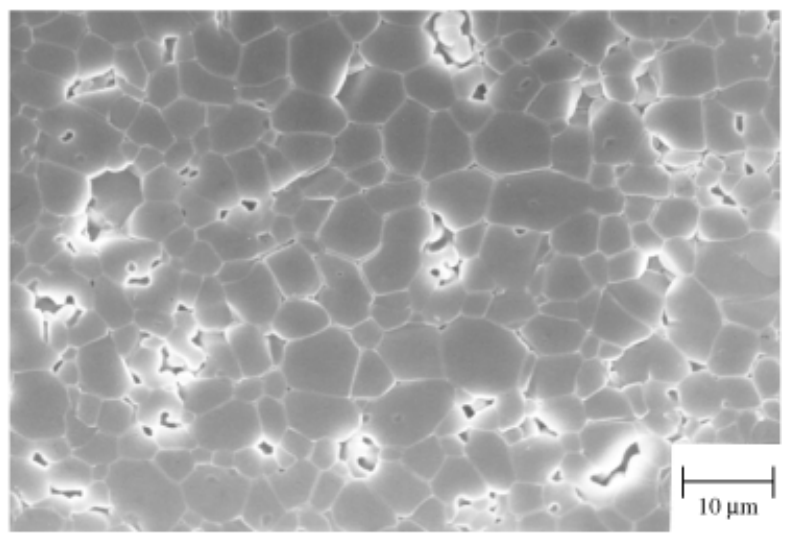

(b)

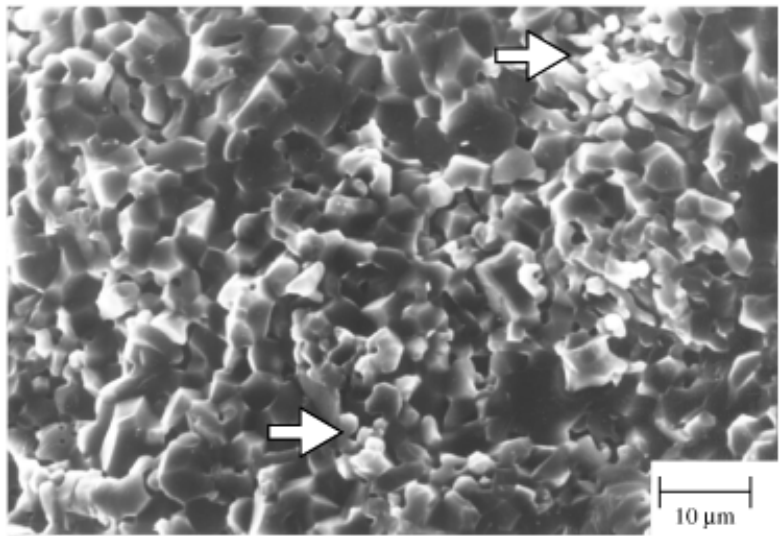

Fig. 5. (a) Microstructure and (b) fracture surface of alumina with $1050 \mathrm{ppm} \mathrm{MgO}$ powder additions showing some poorly sintered areas, as indicated by the arrows. 
(a)

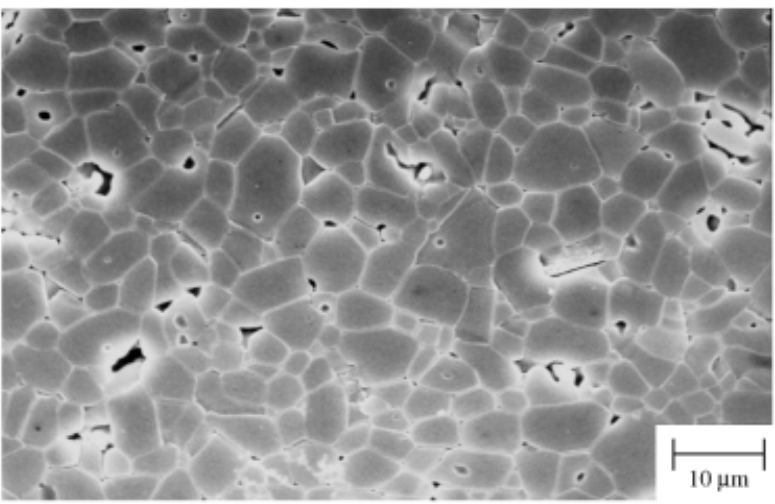

(b)

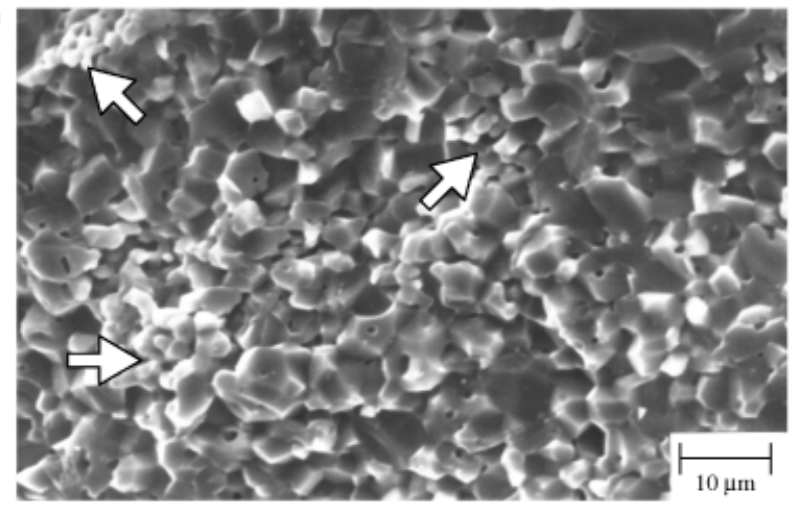

Fig. 6. (a) Microstructure and (b) fracture surface of alumina with 1050 ppm $\mathrm{MgO}$ formed from the $\mathrm{Mg}$-acetate showing some poorly sintered areas, as indicated by the arrows.
Table III. The Average, Maximum, Minimum, and Standard Deviation of the Grain Size of the Sintered Alumina Shown in Figs. 4-7 Measured Using the Line-Intercept Method

\begin{tabular}{lrrrr}
\hline & $\begin{array}{c}\text { Pure } \\
\text { alumina }\end{array}$ & MgO & Mg-acetate & Mg-stearate \\
\hline Average grain size $(\mu \mathrm{m})$ & 5.2 & 6.0 & 5.7 & 6.8 \\
Standard deviation $(\mu \mathrm{m})$ & 3.7 & 2.9 & 2.9 & 2.9 \\
Maximum grain size $(\mu \mathrm{m})$ & 21.7 & 12.9 & 10.8 & 13.4 \\
Minimum grain size $(\mu \mathrm{m})$ & 0.8 & 1.6 & 1.2 & 1.2 \\
\hline
\end{tabular}

the $\mathrm{MgO}$ addition promotes grain growth and the density. The smaller grains in the less dense pure alumina are mainly attributed to the presence of the larger amount of pores, which act as grain growth inhibitors.

The uniformity of the $\mathrm{MgO}$ distribution was examined by EPMA. Fifty areas, all $0.25 \mathrm{~mm} \times 0.25 \mathrm{~mm}$, were scanned for each specimen. Figure 8 demonstrates one area of the specimen that was prepared using the Mg-acetate. It shows the presence of $\mathrm{MgO}$-rich areas. No such areas were found in specimens with $\mathrm{Mg}$-stearate additives or $\mathrm{MgO}$.

\section{(5) Mechanical Properties}

The bending strength results shown in Fig. 9 illustrate that the pure alumina had a low strength of $195 \mathrm{MPa}$. When Mg-stearate was used, the strength increased as the amount of $\mathrm{MgO}$ increased, reaching $302 \mathrm{MPa}$ at $1400 \mathrm{ppm} \mathrm{MgO}$. As the $\mathrm{MgO}$ further increased, the strength decreased. This is very possibly caused by the formation of the second phase, which also has a similar effect on the density. ${ }^{15}$ In comparison, the maximum strengths of the alumina with the addition of $\mathrm{MgO}$ powders and with the Mg-acetate were lower, at 255 and $238 \mathrm{MPa}$, respectively.

\section{Discussion}

The present work shows that the $\mathrm{MgO}$ powders are less effective sintering aids than the $\mathrm{Mg}$-stearate. One of the reasons is that it has a high density or low specific volume, and a low molecular weight of $40.3 \mathrm{~g}$. Thus, to add the same amount of $\mathrm{MgO}$, such as $1050 \mathrm{ppm}$, only $0.065 \mathrm{vol} \%$ of $\mathrm{MgO}$ powders is present in the feedstock. In contrast, the molecular weights of $\mathrm{Mg}$-acetate and Mg-stearate are 214.3 and $590.7 \mathrm{~g}$, respectively. To attain 1050 $\mathrm{ppm} \mathrm{MgO}, 0.893 \mathrm{vol} \%$ of $\mathrm{Mg}$-acetate and $3.40 \mathrm{vol} \%$ of $\mathrm{Mg}$ stearate are required. Thus, the 52 times greater volume of the $\mathrm{Mg}$-stearate provides more uniform $\mathrm{MgO}$ distribution and requires shorter homogenization time.

Moreover, the Mg-stearate has a low melting point of $120^{\circ} \mathrm{C}$ and thus can be mixed with other binder components homoge-

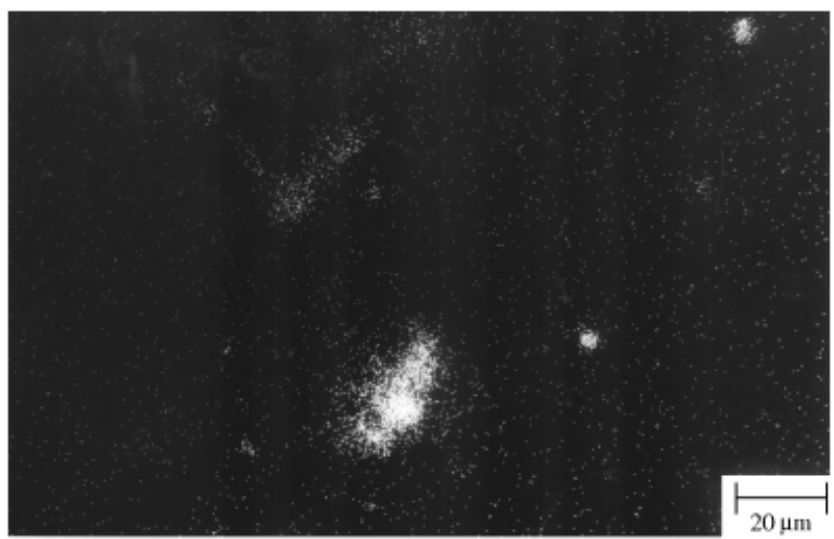

Fig. 8. Mapping of the $\mathrm{Mg}$ element in a specimen that was processed with the Mg-acetate.
Fig. 7. (a) Microstructure and (b) fracture surface of alumina with 1050 ppm $\mathrm{MgO}$ formed from the Mg-stearate showing evenly sintered microstructures. (b)

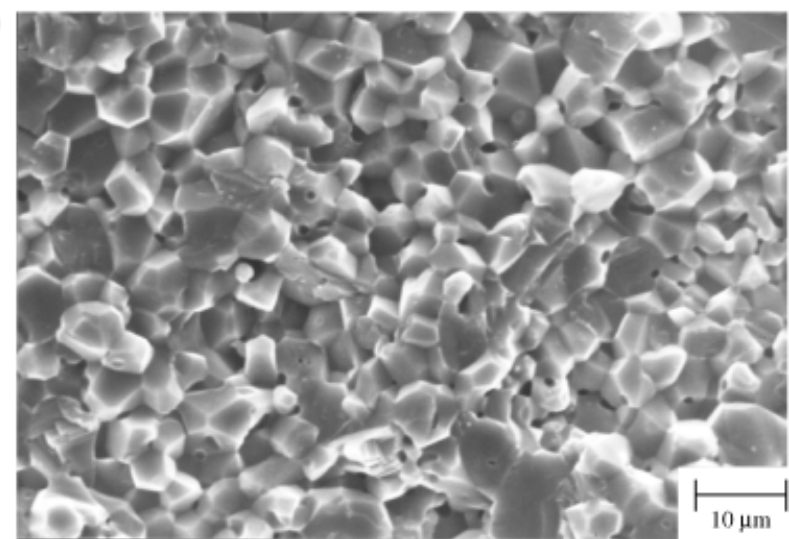




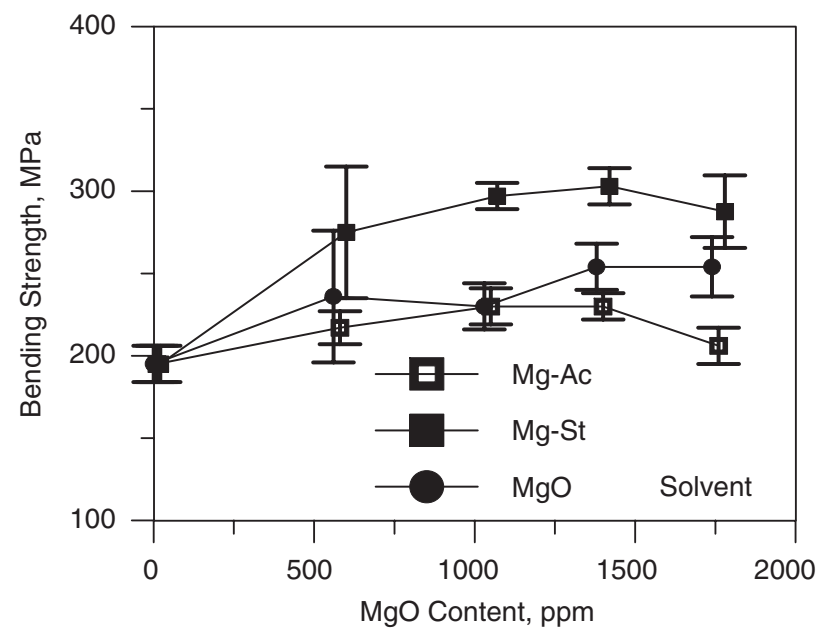

Fig. 9. Bending strength increases as the amount of $\mathrm{MgO}$ increases.

neously in the liquid form during kneading at $150^{\circ} \mathrm{C}$. In contrast, when fine $\mathrm{MgO}$ powders are used, they have to be mixed in the solid particle form. On the other hand, $\mathrm{Mg}$-acetate, despite also being in the liquid form at the kneading temperature of $150^{\circ} \mathrm{C}$, did not provide better results than the $\mathrm{Mg}$-stearate or even the $\mathrm{MgO}$ powder. The most likely reason is that, as it is heated, it melts at $70^{\circ} \mathrm{C}$ and begins to dehydrate between $70^{\circ}$ and $150^{\circ} \mathrm{C}$, as indicated by the TGA curve shown in Fig. 2 and the vapor observed during kneading. Once it dehydrates, it forms solid lumps. This means that if the dehydration occurs slowly, the $\mathrm{Mg}$-acetate can still be mixed well into the feedstock while it remains a liquid. However, if $\mathrm{Mg}$-acetate dehydrates before it is well distributed in the mixing material, the Mg-acetate loses its liquid form and thus its advantage of being mixed uniformly. When such a case happens, the $\mathrm{MgO}$ distribution of the $\mathrm{Mg}$ acetate could even be worse than that of the straight $\mathrm{MgO}$ particles, as the $\mathrm{MgO}$ lump needs to be further pulverized. As indicated by the presence of the $\mathrm{MgO}$-rich area in Fig. 8, early dehydration was very likely the case that occurred in this study. Therefore, the $\mathrm{Mg}$-acetate and $\mathrm{MgO}$ had similar sintered densities, as shown in Fig. 3, while the use of high molecular weight $\mathrm{Mg}$-stearate allows better $\mathrm{MgO}$ distribution, and thus a higher sintered density is obtained.

In addition to the effect of $\mathrm{MgO}$ distribution on the sintered densities, the microstructures and fracture surfaces shown in Figs. 4-7 also indicate that the pore shape was affected. When $\mathrm{Mg}$-stearate was used, the pore size was smaller and the shape was more rounded than in specimens using $\mathrm{MgO}$ powder and $\mathrm{Mg}$-acetate. Because pores with irregular shapes act as flaws and stress concentration regions, the bending strengths of Mg-stearate-containing specimens were thus higher than those of others.

\section{Conclusions}

The density and microstructure of injection-molded alumina are significantly influenced by the $\mathrm{MgO}$ doping method. The addition of $\mathrm{MgO}$ particles does not provide homogeneous distribution and, thus, lower sintered densities and bending strengths were obtained. The use of magnesium acetate, a $\mathrm{MgO}$ precursor, did not improve the dispersion either, as $\mathrm{Mg}$-acetate dehydrated and became solid in the early stage of kneading before it was well mixed with the other components and alumina powders. Thus, it provided no advantage over the method of adding straight $\mathrm{MgO}$ particles. When high molecular weight magnesium stearate was used, the $\mathrm{MgO}$ precursor was intimately mixed into the binder system in the liquid state. The uniform distribution of the $\mathrm{MgO}$, which formed during debinding, led to bettersintered properties than possible when using the straight $\mathrm{MgO}$ particles and $\mathrm{Mg}$-acetate.

\section{Acknowledgment}

The authors wish to thank Mr. C. Y. Kao for his assistance on the EPMA analysis.

\section{References}

${ }^{1}$ R. L. Coble, "Sintering Crystalline Solids. II. Experimental Test of Diffusion Model in Powder Compacts," J. Am. Ceram. Soc., 32 [5] 793-9 (1983).

${ }^{2}$ S. J. Bennison and M. P. Harmer, "A History of the Role of MgO in the Sintering of $\alpha-\mathrm{Al}_{2} \mathrm{O}_{3}$," Ceram. Trans., 7, 13-49 (1990).

${ }^{3}$ S. J. Bennison and M. P. Harmer, "Effect of $\mathrm{MgO}$ Solute on the Kinetics of Grain Growth in $\mathrm{Al}_{2} \mathrm{O}_{3}$," J. Am. Ceram. Soc., 66 [5] C90-2 (1983).

${ }^{4}$ K. A. Berry and M. P. Harmer, "Effect of MgO Solute on Microstructure Development in $\mathrm{Al}_{2} \mathrm{O}_{3}$," J. Am. Ceram. Soc., 69 [2] 143-9 (1986).

${ }^{5}$ N. J. Shaw and R. J. Brook, "Structure and Grain Coarsening During the Sintering of Alumina," J. Am. Ceram. Soc., 69 [2] 107-10 (1986).

${ }^{6}$ A. Cohen, C. P. Van Der Merwe, and A. I. Kingon, "Defect of MgO Dopant Dispersing Method on Density and Microstructure of Alumina Ceramics;" pp. 780-90 in Advances in Ceramics, Vol. 10, Structure and Properties of $\mathrm{MgO}$ and $\mathrm{Al}_{2} \mathrm{O}_{3}$ Ceramics, Edited by W. K. Kingery. Am. Ceram. Soc., Columbus, OH, 1984.

${ }^{7}$ A. Mocellin and W. D. Kingery, "Microstructural Changes During Heat Treatment of Sintered Alumina," J. Am. Ceram. Soc., 56 [6] 309-14 (1973).

${ }^{8}$ P. E. C. Franken and A. P. Gehring, "Grain Boundary Analysis of MgODoped $\mathrm{Al}_{2} \mathrm{O}_{3}$," J. Mater. Sci., 16, 384-8 (1981).

${ }^{9}$ P. J. Jorgensen, "Modification of Sintering Kinetics by Solute Segregation in $\mathrm{Al}_{2} \mathrm{O}_{3}$, , J. Am. Ceram. Soc., 48 [4] 207-10 (1965).

${ }^{10}$ C. A. Handwerker, P. A. Morris, and R. L. Coble, "Effects of Chemical Inhomogeneities on Grain Growth and Microstructure in $\mathrm{Al}_{2} \mathrm{O}_{3}$," J. Am. Ceram. Soc., 72 [1] 130-6 (1989).

${ }^{11}$ R. M. German and A. Bose, Injection Molding of Metals and Ceramics. MPIF, Princeton, NJ, 1997.

${ }^{12}$ E. E. Underwood, Quantitative Stereology. Addison-Wesley, Reading, MA, 1970 .

${ }^{13}$ Me. E. UnP. Miranzo, L. Tabernero, J. Moya, and J. Jurado, "Effect of Sintering Atmosphere on the Densification and Electrical Properties of Alumina," J. Am. Ceram. Soc., 73 [7] 2119-21 (1990).

${ }^{14}$ F. J. Klung, W. D. Pasco, and M. P. Borom, "Microstructure Development of Aluminum Oxide: Graphite Mixture During Carbothermic Reaction," J. Am. Ceram. Soc., 65 [12] 619-24 (1982).

${ }^{15}$ J. G. J. Peelen, "Influence of $\mathrm{MgO}$ on the Evolution of the Microstructure of Alumina;" pp. 443-53 in Materials Science Research, Vol. 10, Sintering and Catalysis, Edited by G. C. Kuczynski. Plenum, New York, 1975. 